\title{
Editorial \\ Challenges and New Trends in Power Electronic Devices Reliability
}

\author{
Elio Chiodo ${ }^{1, *}$, Pasquale De Falco ${ }^{2, *(D)}$ and Luigi Pio Di Noia ${ }^{3, *(D)}$ \\ 1 Department of Industrial Engineering, University of Naples Federico II, 80125 Naples, Italy \\ Department of Engineering, University of Naples Parthenope, 80143 Naples, Italy \\ 3 Department of Electrical Engineering and Information Technology, University of Naples Federico II, \\ 80125 Naples, Italy \\ * Correspondence: chiodo@unina.it (E.C.); pasquale.defalco@uniparthenope.it (P.D.F.); \\ luigipio.dinoia@unina.it (L.P.D.N.)
}

check for updates

Citation: Chiodo, E.; De Falco, P.; Di Noia, L.P. Challenges and New Trends in Power Electronic Devices Reliability. Electronics 2021, 10, 925. https://doi.org/10.3390/ electronics10080925

Received: 29 March 2021

Accepted: 7 April 2021

Published: 13 April 2021

Publisher's Note: MDPI stays neutral with regard to jurisdictional claims in published maps and institutional affiliations.

Copyright: (C) 2021 by the authors Licensee MDPI, Basel, Switzerland. This article is an open access article distributed under the terms and conditions of the Creative Commons Attribution (CC BY) license (https:// creativecommons.org/licenses/by/ $4.0 /)$.

\section{Introduction}

Power electronic devices are expected to play an ever more fundamental role in unlocking the potentialities of smart power systems and in developing more electric ground and air transportation systems. The reliability of power electronic devices at different hierarchical levels (single component, single device, installation and system) becomes a crucial point in this framework, as failures may determine technical, economical and safety issues that should be carefully addressed at the design and maintenance stages.

Power electronic devices are subject to thermal, electrical and mechanical stresses, which can be assessed through consolidated, traditional techniques [1-4]. However, today these devices are expected to operate under challenging environmental conditions (e.g., high altitudes in more electric aircrafts or high temperatures on photovoltaic (PV) installations), undermining the effectiveness of traditional approaches that are typically based on historical failure data, fault rates or past observed scenarios. In fact, the rapid evolution of power electronic technologies and the ever more challenging operating frameworks pose severe limitations on the trustworthiness of available reliability data, as they are typically related to incoherent operating conditions [1-4].

\section{The Special Issue}

The Electronics Special Issue on Challenges and New Trends in Power Electronic Devices Reliability collected contributions on methodologies and approaches for the analysis of reliability in power electronic devices at different hierarchical levels, covering multiple fields of applications ranging from PVs to motor drives to LED lamps. The editorial resume of contributions is listed below:

- The reliability of PV AC/DC converters was analyzed in [5], with a finalization related to maintenance and repair activities. A $46 \mathrm{MW}$ large-scale grid-connected PV plant was considered in the reliability analysis, with a detailed comparison to the maintenance reports collected for a three-year span, also leading to an estimation of the overall losses due to unavailability of the system. The reliability of a hybrid PV-battery installation was considered in [6], with a comparison of the DC- and AC-coupled configurations. Therefore, DC/DC and DC/AC converter units were considered, and the reliability was evaluated at different hierarchical levels;

- The gallium nitride high-electron mobility transistor (GaN HEMT) technology was assessed in [7] with reference to its typical cascode structure. Single-event effects on the cascode were studied using a technical computer-aided design for heavy ion experiments. An interesting outcome of the research was that the enhancement of the ionization mechanism at the gate edge may increase the performance in terms of leakage; 
- The lifetime estimation of discrete SiC power MOSFETs for motor drives was performed in [8]. The thermal stress was modeled through a tool that exploited the Coffin-Manson theory, rainflow counting and Miner's rule for the estimation of the lifetime under variable mission profiles, allowing for the generalization of the procedure to different final purposes;

- A multi-chip IGBT module failure monitoring method was presented in [9] to track solder layer fatigue or bond wire fall-off. The method was based on the module transconductance, which was able to represent the failure mechanism of the IGBT and the relationship between chip failure, bond wire failure and the transmission characteristic curve of the IGBT module. Thermal stress on the IGBT operating in microgrids was evaluated in [10]. The aging process of the IGBT was considered in an online evaluation through a fusion algorithm that combined condition monitoring and reliability evaluation. An electrothermal coupling model obtained the junction temperature data, considering the microgrid inverter topology and the IGBT features, and a segmented long short-term memory algorithm was exploited to predict the aging process;

- The work in [11] quantified the impact of overvoltages on high-power thyristors, investigating the effects of the initial voltage of the energy storage capacitor, the discharge time intervals and the load resistance on the reverse recovery currents. On the basis of the outcomes, an improved topology was then developed to damp the surge energy and to mitigate the reverse recovery currents;

- A reliability forecasting model that targeted the insulation of power components subjected to varying harmonics was presented in [12]. The model focused on the role played by low percentiles of time to failure, typically selected as the rated life in the framework of the modern probabilistic design of components, and it treated all the odd voltage harmonics from the fifth to the twenty-fifth;

- LED lamps were investigated in $[13,14]$. The design of a new LED lamp concept, with attention to energy-saving, comfort and reliability purposes was presented in [13]. The lifetime of LED lamps was considered in [14], with a Norris-Landberg model that analyzed the probability of failure and the lifetime with reference to solder joint cracks. Over 1800 events were considered in the experimental validation process;

- A review of the state of the art of the condition monitoring of power electronics devices is in [15].

\section{Discussion and Future Contributions}

The potentialities unlocked by high-performance power electronic devices in smart power systems and more electric transportation are well recognized, although studies on the reliability of these components in challenging and severe conditions are far from being established. The integration of power electronics in different topologies and hybrid systems, together with the analysis of still unexplored fields such as full electric aircrafts and decentralized smart grids, will likely be the object of extensive research in the next decade. Future contributions on the reliability of power system components cannot neglect these aspects and should try to overcome the common bottleneck of the lack of field data in real-world challenging contexts.

Author Contributions: E.C., P.D.F. and L.P.D.N. were equally involved in the conceptualization of the Special Issue and in its entire editorial process. Writing-original draft preparation, P.D.F.; writing-review and editing, E.C., P.D.F. and L.P.D.N. All authors have read and agreed to the published version of the manuscript.

Funding: This research received no external funding.

Acknowledgments: E.C., P.D.F. and L.P.D.N. gratefully thank the authors for providing their contributions to the Special Issue and all the reviewers involved at any stage of the peer review processes. E.C., P.D.F. and L.P.D.N. also acknowledge the Electronics Editorial Office for maintaining the rigorous revision process and for ensuring the timely publication of the contents. 
Conflicts of Interest: The authors declare no conflict of interest.

\section{References}

1. Yang, S.; Xiang, D.; Bryant, A.; Mawby, P.; Ran, L.; Tavner, P. Condition monitoring for device reliability in power electronic converters: A review. IEEE Trans. Power Electron. 2010, 25, 2734-2752. [CrossRef]

2. Song, Y.; Wang, B. Survey on reliability of power electronic systems. IEEE Trans. Power Electron. 2012, 28, 591-604. [CrossRef]

3. Wang, H.; Liserre, M.; Blaabjerg, F. Toward reliable power electronics: Challenges, design tools, and opportunities. IEEE Ind. Electron. Mag. 2013, 7, 17-26. [CrossRef]

4. Falck, J.; Felgemacher, C.; Rojko, A.; Liserre, M.; Zacharias, P. Reliability of power electronic systems: An industry perspective. IEEE Ind. Electron. Mag. 2018, 12, 24-35. [CrossRef]

5. Spertino, F.; Amato, A.; Casali, G.; Ciocia, A.; Malgaroli, G. Reliability Analysis and Repair Activity for the Components of $350 \mathrm{~kW}$ Inverters in a Large Scale Grid-Connected Photovoltaic System. Electronics 2021, 10, 564. [CrossRef]

6. Sandelic, M.; Sangwongwanich, A.; Blaabjerg, F. Reliability Evaluation of PV Systems with Integrated Battery Energy Storage Systems: DC-Coupled and AC-Coupled Configurations. Electronics 2019, 8, 1059. [CrossRef]

7. Liang, Y.; Chen, R.; Han, J.; Wang, X.; Chen, Q.; Yang, H. The Study of the Single Event Effect in AlGaN/GaN HEMT Based on a Cascode Structure. Electronics 2021, 10, 440. [CrossRef]

8. Barbagallo, C.; Rizzo, S.A.; Scelba, G.; Scarcella, G.; Cacciato, M. On the Lifetime Estimation of SiC Power MOSFETs for Motor Drive Applications. Electronics 2021, 10, 324. [CrossRef]

9. Wang, C.; He, Y.; Wang, C.; Li, L.; Wu, X. Multi-Chip IGBT Module Failure Monitoring Based on Module Transconductance with Temperature Calibration. Electronics 2020, 9, 1559. [CrossRef]

10. Wang, C.; He, Y.; Wang, C.; Wu, X.; Li, L. A Fusion Algorithm for Online Reliability Evaluation of Microgrid Inverter IGBT. Electronics 2020, 9, 1294. [CrossRef]

11. Wei, J.; Li, Z.; Li, B. Investigation of Reverse Recovery Current of High-Power Thyristor in Pulsed Power Supply. Electronics 2020, 9, 1292. [CrossRef]

12. Mazzanti, G.; Diban, B.; Chiodo, E.; De Falco, P.; Di Noia, L.P. Forecasting the Reliability of Components Subjected to Harmonics Generated by Power Electronic Converters. Electronics 2020, 9, 1266. [CrossRef]

13. Lee, C.-T.; Ho, P.-T. Energy-Saving Research on New Type of LED Sensor Lamp with Low-Light Mode. Electronics 2020, 9 , 1649. [CrossRef]

14. Pinti, F.; Belli, A.; Palma, L.; Gattari, M.; Pierleoni, P. Validation of Forward Voltage Method to Estimate Cracks of the Solder Joints in High Power LED. Electronics 2020, 9, 920. [CrossRef]

15. Susinni, G.; Rizzo, S.A.; Iannuzzo, F. Two Decades of Condition Monitoring Methods for Power Devices. Electronics 2021, 10, 683. [CrossRef] 